\title{
XLI. Influence of atomic weight
}

\section{Thomas Carnelley D.Sc.}

To cite this article: Thomas Carnelley D.Sc. (1879) XLI. Influence of atomic weight, Philosophical Magazine Series 5, 8:50, 368-381, DOI: 10.1080/14786447908639698

To link to this article: http://dx.doi.org/10.1080/14786447908639698

$$
\text { 曲 Published online: } 13 \text { May } 2009 .
$$

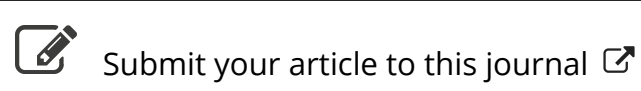

\footnotetext{
Џll Article views: 2
}

Q View related articles $\longleftarrow$ 
the variation of specific gravity and the electric properties of steel, the 'T. E. H., specific resistance, and magnetic moment are in some very intimate way connected with the volume of a unit of mass. This would imply a connexion of these phenomena with the intermolecular spaces of steel.

In conclusion, it gives me great pleasure to acknowledge my indebtedness to Prof. Kohlrausch for much kind assistance throughout the course of the experiments.

Phys. Inst. Univ. Würzburg, February 1879.

XLI. Influence of Atomic Weight. By Thomas Carnelley, D.Sc., Assistant Lecturer on Chemistry in the Ovens College.

[Continued from p. 324.]

\section{Influence of Atomic Weight on the Physical Properties of Compounds.}

QO far, we have endeavoured to show the influence of atomic $D$ weight on the properties of the elements ; we shall now continue this subject with regard to the influence of atomic weight on the physical properties of compounds.

Mendeljeff"s Law of Periodicity runs thus :- "The properties of the elements are a periodic function of their atomic weights." This law may be supplemented as follows :- "The properties of the compounds of the elements are a periodic function of the atomic weights of their constituent elements." In a paper recently (June 19, 1879) read before the Royal Society the author has shown that this holds good as regards the melting- and boiling-points and heats of formation of the normal halogen compounds of the elements and of certain compounds of the elements with monatomic alcohol radicals; and for the present we shall limit ourselves to these.

A. Melting-and Boiling-points and Heats of Formation.

I. Normal Chlorides, Bromides, and Iodides of the Elements.-In whatever way the melting-points, boiling-points, and heats of formation of these compounds be arranged, provided only they are arranged systematically, we always find that certain definite and regular relations may be traced between the numerical values for the above-mentioned physical properties and the atomic weights of the compounds. Some of the more important conclusions arrived at are as follows :-

(1) The melting-and boiling-points and heats of formation of 
the normal halogen compounds of the elements are a periodic function of the atomic weights of the constituent elements. For if the elements be arranged in the order of their atomic weights, then the melting-points, boiling-points, and heats of formation of their halogen compounds rise and fall periodically nine times, these periods corresponding exactly with Mendeljeft's nine series of elements. The maxima occur at the positive and the minima at the negative end of each series.

(2) The influence of the halogen on these same physical properties increases with the number of its atoms in the compound, thus :-

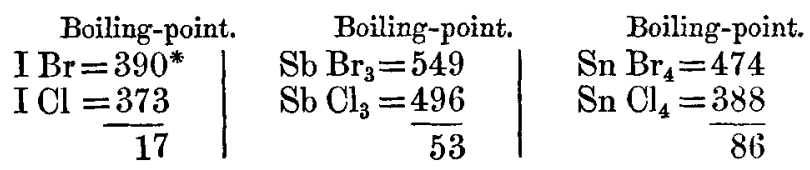

(3) In any normal halogen compound the influence of either of the elements on the melting-or boiling-point increases with its own atomic weight, and decreases with the atomic weight of the other element. Thus:-

$$
\begin{array}{l|r}
\quad \text { Melting-point. } & \begin{array}{r}
\text { Melting-point. } \\
\mathrm{Sb} \mathrm{Br} r_{3}=363
\end{array} \\
\mathrm{As} \mathrm{Br}_{3}=\frac{295}{68} & \mathrm{Sb}_{3}=438 \\
\mathrm{Sb} \mathrm{Br}_{3}=\frac{363}{75}
\end{array}
$$

In each of the above pairs of compounds which contain one element in common the melting-point increases with the atomic weight of the variable element, and that whether the latter be the positive or negative constituent-thus showing that the influence of an element on the melting-point of one of its compounds increases with its own atomic weight. That it decreases with the atomic weight of the other element is shown by the following examples:-

$$
\begin{aligned}
& \text { Melting-point. } \\
& \mathrm{As} \mathrm{I}_{3}=419 \\
& \mathrm{As} \mathrm{Br}_{3}=295 \\
& \overline{124}
\end{aligned}
$$

Melting-point.

Here the substitution of $\mathrm{I}$ for $\mathrm{Br}$ produces a larger increase in the melting-point in the case of the As than in that of the

* These numbers are all reckoned from the absolute zero $-273^{\circ} \mathrm{C}$., and this is the case with all melting-points and boiling-points subsequently referred to. 
Sb compounds, the atomic weight of As being less than that of $\mathrm{Sb}$. Again

Melting-point.

$\mathrm{Sn} \mathrm{Br}_{4}=303$
$\mathrm{Si} \mathrm{Br}_{4}=\frac{260}{43}$
Melting-point.

$$
\begin{aligned}
& \mathrm{Sn}_{4}=419 \\
& \mathrm{Si} \mathrm{I}_{4}=393
\end{aligned}
$$

As before, the substitution of Sn for Si produces a greater influence on the melting-point in the case of the bromides than in that of the iodides, $i$. $e$. where the atomic weight of the negative element is least.

(4) The melting-or boiling-point or heat of formation of a bromide is always nearer to that of the corresponding chloride than to that of the corresponding iodide; and the melting-or boiling-points of the halogen compounds of the middle member of three consecutive elements of the same group are always nearer to those of the first (i. e. the one with least atomic weight) than to those of the last member. Thus:-

$$
\begin{aligned}
& \text { Melting-point }=\underbrace{\mathrm{SbCl}_{3} .}_{\text {Difference }=18} \quad \underbrace{\mathrm{SbBr}^{\circ} .}_{75} \underbrace{363} \underbrace{\begin{array}{l}
\mathrm{SbI}_{3} \\
438
\end{array}} \\
& \text { Melting-point }=\underbrace{\underbrace{\mathrm{NaCl} .}}_{\text {Difference }=64} \quad \underbrace{\mathrm{NaBr} .}_{80} \quad \underbrace{1045} \\
& \text { Boiling-point }=\underbrace{\mathrm{PCl}_{3} .}_{\text {Difference }=54} \quad \begin{array}{l}
\mathrm{AsCl}_{3} . \\
405
\end{array} \underbrace{\begin{array}{r}
\mathrm{SbCl}_{3} \\
496
\end{array}}_{91}
\end{aligned}
$$

The former of these phenomena probably depends on the fact that the atomic weight of $\mathrm{Br}$ is nearer to that of $\mathrm{Cl}$ than to that of $I$; and the latter on the fact that the atomic weight of the middle member of three consecutive elements of the same group is always less than the mean of those of the other two elements; thus-

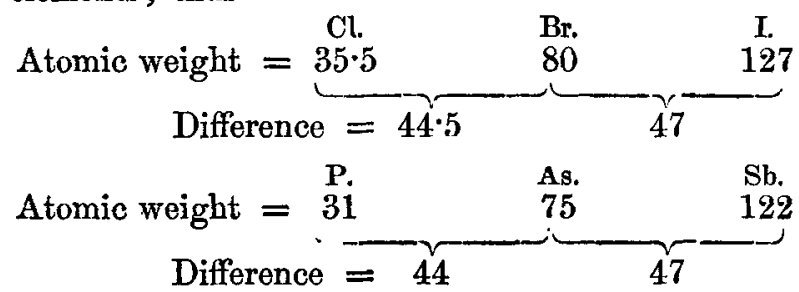

We have here, therefore, a good instance of the influence of atomic weight on the physical properties of compounds. 
(5) The melting- and boiling-points of the halogen compounds of the elements belonging to the first and second groups of Mendeljeff's classification are widely separated from those of the other groups, being in fact considerably higher. Different relations, too, often appear to exist between the melting-points of even members of these two groups from those which exist between groups (3-7) inclusive; while the compounds of the elements which are often placed in the odd divisions of the first and second groups are generally altogether irregular. In the case of the odd members of the first group, this may be explained by the fact that it is very uncertain whether $\mathrm{Cu}, \mathrm{Ag}$, and $\mathrm{Au}$ really belong to the same group as $\mathrm{Na}$ or not, as pointed out by Mendeljeff in his memoir on the Periodic Law ; for he places these elements not in the first group along with $\mathrm{Na}$, but in the eighth with $\mathrm{Fe}, \mathrm{Pd}, \mathrm{Pt}$, \&c.

In the paper above referred to it has been shown how the preceding relations may be applied

(1) To the calculation of unknown melting- and boilingpoints.-The following are instances of melting-points predicted by this method having been verified by experiment :-

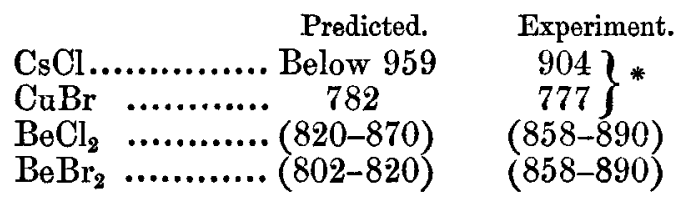

(2) To the determination of the atomic weights of elements when the application of the methods of specific heat and vapour-density are inadmissible or uncertain. By this means the atomic weight of $B e$ has been found to be $9 \cdot 2$, thus agreeing with the determination of the specific heat made by Fmmerson Reynolds, and proving Nilsson and Pettersen's determination to be incorrect; for they found a value for the specific heat corresponding to the atomic weight $13 \cdot 8$.

As far as existing data allow us to judge, the compounds of the elements with fluorine and also with monatomic organic radicals, likewise obey the same laws as those of the halogen compounds. The fluorides, however, cannot be strictly compared with the chlorides, bromides, and iodides, since $\mathrm{F}$ is an even member of the seventh group; whereas $\mathrm{Cl}, \mathrm{Br}$, and $\mathrm{I}$ are odd members.

Boiling-points of Organic Compounds in general.-The boiling-points and melting-points of carbon compounds depend:-(1) On the atomic weights or nature of the consti-

* These two numbers have not been previously published. 
tuent elements ; (2) On the position or arrangement of these elements in the molecule. The first of these is more especially rendered evident in homologous series, and the second in isomeric compounds. Of the latter, however, we shall have little or nothing to say in the present communication, as it is intended, if opportunity admits, to refer to it at length in a subsequent paper.

The connexion between the boiling-points and composition of organic compounds as pointed out by Kopp (Ann. Chem. Pharm. xcvi. pp. 2, 230, xcviii. pp. 267,367 ) is so well known that it will be unnecessary to go into detail with regard to it. It will be sufficient to mention his more important conclusions :- (1) Analogous compounds presenting the same difference of composition very frequently differ by the same amount in their boiling-points. A compound containing $x \mathrm{C}$ more or less than another compound of analogous function generally boils at a temperature $29 x$ degrees bigher or lower than the latter; and if it contains $x \mathrm{H}$ more or less, it generally boils at $5 x$ degrees lower or higher. These rules are best applied in the case of compounds belonging to the same homologous series. In the fatty acids $\mathrm{C}_{n} \mathrm{H}_{2 n} \mathrm{O}_{2}$ and corresponding alcohols and compound ethers each addition of $\mathrm{CH}_{2}$ raises the boiling-point, on an average, by $(29-2 \times 5)=19^{\circ}$, thus agreeing with the above rule. (2) An acid $\mathrm{C}_{n} \mathrm{H}_{2 n} \mathrm{O}_{2}$ boils $40^{\circ}$ above the corresponding alcohol $\mathrm{C}_{n} \mathrm{H}_{2 n+2} \mathrm{O}$. (3) A compound ether $\mathrm{C}_{n} \mathrm{H}_{2 n} \mathrm{O}_{2}$ boils $82^{\circ}$ below the acid isomeric with it. In other series of compounds the difference in boiling-point corresponding to a difference of $\mathrm{CH}_{2}$ is mostly regular; but it is sometimes more and sometimes less than 19. As a rule, the greater the quantity of $\mathrm{O}$ in a compound, the smaller is the effect on the boiling-point of an increase of $\mathrm{CH}_{2}$ in the composition. In the halogen compounds of the alcohol radicals $\mathrm{C}_{n} \mathrm{H}_{2 n+1}$, a difference of $\mathrm{CH}_{2}$ corresponds to a difference of 24 to 31 degrees in the boiling-point. As an instance of boilingpoints calculated in this way being subsequently verified by experiment, I give the following :-

\begin{tabular}{|c|c|c|c|}
\hline & \\
\hline & & \\
\hline & \\
\hline \\
\hline \multicolumn{4}{|c|}{ 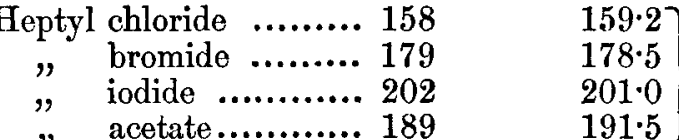 } \\
\hline
\end{tabular}

Notwithstanding, however, the near agreement of many of the calculated with the experimental boiling-points, Linnemann (Ann. Ch. Pharm. clxii. p. 39), who has carefully de* C. F. Cross (Chem. Soc. Journ, 1877, ii. p. 128). 
termined the boiling-points of a large number of compounds, concludes that the differences of boiling-point between consecutive members of homologous series are by no means exactly equal, but exhibit considerable variation, even as much as $3^{\circ}$.

The following are a few further examples of regularity in the boiling-points of organic compounds which have recently been pointed out.

In silicon compounds the substitution of $\left(\mathrm{C}_{2} \mathrm{H}_{5}\right)$ for $\mathrm{Cl}$ raises the boiling-point, as does also an increase in the number of oxygen atoms (Ladenburg, Ann. Ch. Pharm. clxiv. p. 300):--

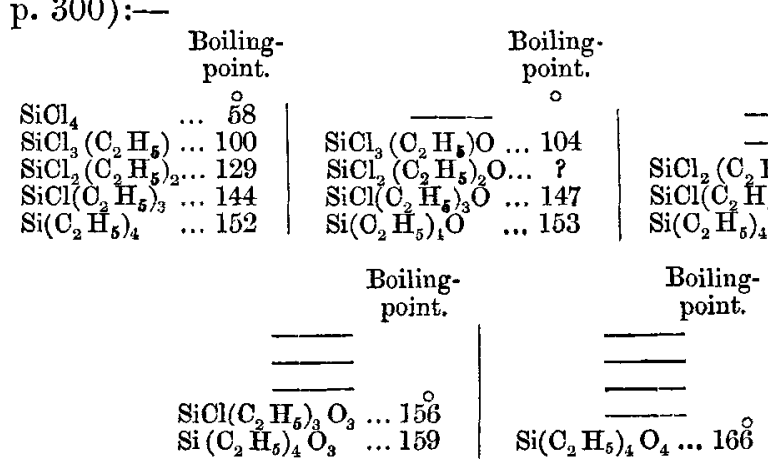

Here the differences between every two consecutive members of each series diminish as we pass down each vertical column, $i$. e. as the number of chlorine atoms replaced by $\mathrm{C}_{2} \mathrm{H}_{5}$ increases; and these same differeaces also diminish in each horizontal line from left to right, $i$. $e$. as the number of $O$ atoms increases. The differences between each two consecutive members of a horizontal series increase from left to right, $i$. $e$. with the number $0 \hat{i} \mathrm{O}$ atoms.

Mendeljeff has called attention to the fact that $\mathrm{Si}$ compounds boil lower than the corresponding $\mathrm{C}$ compounds.

The iodides of the alcohol-radicals always boil $53^{\circ}$ higher than the corresponding amides (Linnemann, Ann. Ch. Pharm. clxii. p. 12), thus :-

\begin{tabular}{|c|c|c|c|c|c|c|}
\hline & Ethyl. & Propyl. & Butyl. & Isobutyl. & $\begin{array}{c}\text { Tertiary } \\
\text { butyl. }\end{array}$ & Amyl. \\
\hline $\mathrm{T}=\ldots \ldots \ldots$ & 72 & $10 \stackrel{\circ}{2} 2$ & 1299 & $120^{\circ} \cdot 6$ & 98.5 & 148.0 \\
\hline $\mathrm{N} \cdot \mathrm{I}_{2}=\ldots$ & $18 \cdot 7$ & $49 \cdot 0$ & 76.5 & $67 \cdot 5$ & 460 & $95 \cdot 0$ \\
\hline Difference & $53 \cdot 3$ & $53 \cdot 2$ & $53 \cdot 4$ & $53 \cdot 1$ & $52 \cdot 5$ & $53 \cdot 0$ \\
\hline
\end{tabular}

Salomon (Journ. f. Chem. [2] vi. p. 433) has shown that Phil. Mag. S. 5. Vol. 8. No. 50. Nov, 1879. 
in the case of the ethyl carbonates and ethyl sulphocarbonates, the introduction of an atom of $\mathrm{S}$ into the ethylated radical is accompanied by a rise of $40^{\circ}$ in the boiling-point, and by a rise of $44^{\circ}$ when the $S$ is introduced into the carbonyl group, except as regards the first member of the series :-

Boiling-point...125

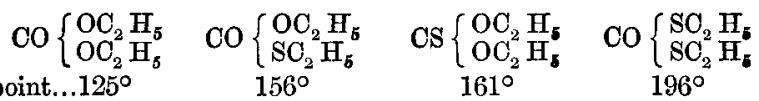

Boiling-point ... $200^{\circ}$

$$
\mathrm{CS}\left\{\begin{array} { l } 
{ \mathrm { OC } _ { 2 } \mathrm { H } _ { 5 } } \\
{ \mathrm { SC } _ { 2 } \mathrm { H } _ { 5 } }
\end{array} \quad \mathrm { CS } \left\{\begin{array}{l}
\mathrm{SO}_{2} \mathrm{H}_{\mathbf{5}} \\
\mathrm{SO}_{2} \mathrm{H}_{5}
\end{array}\right.\right.
$$

From the following Table it is seen that an ethereal salt of a hydroxy-acid boils $20^{\circ}$ higher than its methoxy derivative, and that the ethyl salts of a hydroxy-and an ethoxy-acid have nearly the same boiling-point. Further, the boiling-point of an ethereal salt rises $20^{\circ}$ for the first addition of $\mathrm{CH}_{2}$ to the alcohol-radical and $26^{\circ}$ for the second; but only $6^{\circ}$ and $8^{\circ}$ respectively for a similar addition to the saline radical (Schreiner, Ber. deut. chem. Ges. xii. p. 179). Again, the methyl and ethyl acids boil exactly $40^{\circ}$ higher than their corresponding ethyl salts.

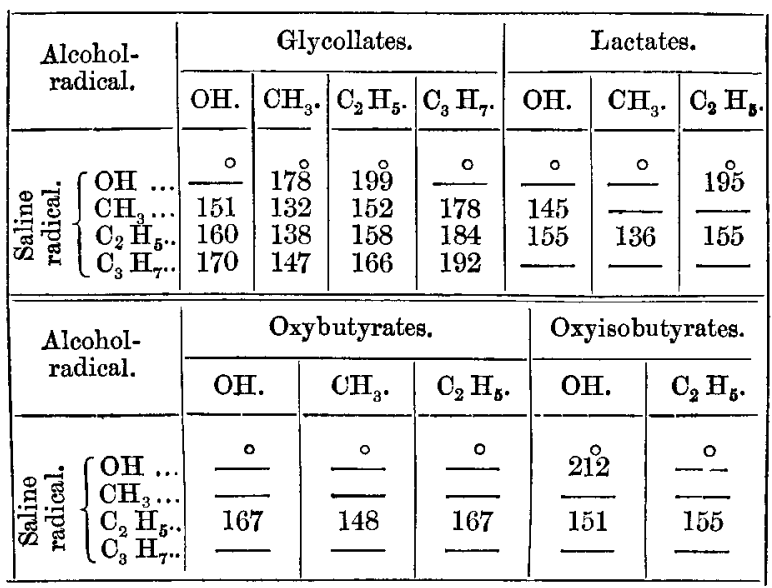

Those benzene hydrocarbons containing an even number of methyl groups are solid, whereas those containing an odd number are liquid, or melt very much lower. The difference between the boiling-points also changes periodically from $30^{\circ}$ to $25^{\circ}$ (Jannasch, Ann. Chem. clxxvi. p. 283). 'These facts are probably due to the circumstance that in those hydrocarbons containing an even number of methyl groups the latter 
are symmetrically arranged; whilst in those containing an odd number the arrangement is generally asymmetrical.

\begin{tabular}{|c|c|c|c|c|c|}
\hline & $\begin{array}{l}\text { Benzene, } \\
\mathrm{C}_{6} \mathrm{H}_{6^{*}}\end{array}$ & $\begin{array}{c}\text { Toluene, } \\
\mathrm{C}_{6} \mathrm{H}_{6} \mathrm{CH}_{3} .\end{array}$ & $\begin{array}{l}\text { Paraxylene. } \\
\mathrm{C}_{6} \mathrm{H}_{4}\left(\mathrm{CH}_{3}\right)_{2}\end{array}$ & $\begin{array}{c}\text { Pseudo- } \\
\text { cumene. } \\
\mathrm{C}_{6} \mathrm{H}_{3}\left(\mathrm{CH}_{3}\right)_{3}\end{array}$ & $\begin{array}{c}\text { Durene. } \\
\mathrm{C}_{6} \mathrm{H}_{2}\left(\mathrm{CH}_{3}\right)_{4}\end{array}$ \\
\hline $\left.\begin{array}{c}\text { Melting- } \\
\text { point. }\end{array}\right\}=$ & $7^{\circ}$ & Iiquid. & $15^{\circ}$ & Liquid. & $80^{\circ}$ \\
\hline $\left.\begin{array}{c}\text { Boiling- } \\
\text { point. }\end{array}\right\}=$ & $81^{\circ}$ & $111^{\circ}$ & $136^{\circ}$ & $166^{\circ}$ & $191^{\circ}$ \\
\hline
\end{tabular}

Groebe (Ber. deut. chem. Ges. vii. p. 1629) has shown that, as a general rule, diphenylene compounds boil $40^{\circ}$ higher than the corresponding compounds of diphenyl, phenanthrene alone being an exception; thus :-

\begin{tabular}{|c|c|c|c|c|}
\hline & $\begin{array}{c}\begin{array}{c}\text { Benzo- } \\
\text { phenone, } \\
\mathrm{C}_{6} \mathrm{H}_{5} \backslash \mathrm{CO} . \\
\mathrm{O}_{8} \mathrm{H}_{\overline{5}}\end{array}>\mathrm{CO} .\end{array}$ & $\begin{array}{l}\text { Diphenylene } \\
\text { ketone, } \\
\mathrm{C}_{6} \mathrm{H}_{4} \backslash \\
\mathrm{C}_{6} \mathrm{H}_{4}\end{array}$ & $\begin{array}{l}\text { Diphenyl } \\
\text { methane, } \\
\mathrm{C}_{6} \mathrm{H}_{5} \backslash \mathrm{CH}_{2} \\
\mathrm{C}_{6} \mathrm{H}_{5}\end{array}$ & $\begin{array}{l}\text { Diphenylene } \\
\text { methane, } \\
\mathrm{C}_{6} \mathrm{H}_{4} \backslash \mathrm{CH}_{2} . \\
\mathrm{C}_{6} \mathrm{H}_{4}\end{array}$ \\
\hline $\left.\begin{array}{c}\text { Boiling- } \\
\text { point. }\end{array}\right\}=$ & $295^{\circ}$ & $336^{\circ}$ & $262^{\circ}$ & $302^{\circ}$ \\
\hline
\end{tabular}

As regards the boiling-points of isomerides, Naumann (Ber. dent. chem. Ges. vii. pp. 173, 206) has pointed out that the simple chain formulæ allow of greater condensation of the molecule, and consequently give a higher boiling-point; whilst the more this form is disturbed by side chains, the lower the boiling-points. Also, the boiling-points of metamerides of analogous constitution and containing $\mathrm{O}$, are the lower the nearer the $O$ is to the centre of the chain of atoms; thus:-

Boiling-point.

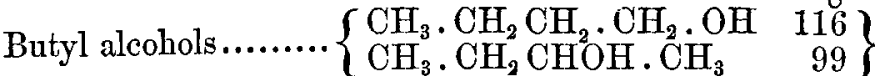

$$
\begin{aligned}
& \text { Methylpropyl ether... } \left.\mathrm{CH}_{3} \cdot \mathrm{CH}_{2} \mathrm{CH}_{2} \cdot \mathrm{O} . \mathrm{CH}_{3} \quad 51\right\} \\
& \text { Diethyl ether .......... } \left.\mathrm{CH}_{3} \cdot \mathrm{CH}_{2} \cdot \mathrm{O} . \mathrm{CH}_{2} \cdot \mathrm{CH}_{3} \quad 35\right\}
\end{aligned}
$$

The theory has been advanced by Burden (Phil. Mag. [4] xli. p. 528) that at the boiling-point (Bar. $=760$ ) the velocity of the molecules is a constant for all liquids, viz. $=1140$ feet per second. This number is obtained by the use of the equation

$$
v \text { (at b.-p.) }=\frac{273+\text { b.-p. }}{273} \sqrt{\frac{\left(\text { velocity of } H \text { gas at } 0^{\circ}\right)^{2}}{\text { vapour-density of the liquid }}},
$$

the velocity of $\mathrm{H}$ at $0^{\circ} \mathrm{C}$. being $=6050$ feet per second. For the raison d'etre of this equation, reference must be made to the original paper. Burden gives a large number of Tables $2 \mathrm{C} 2$ 
in support of his view. The following are the mean velocities calculated by him for several series of compounds :-

Paraffins................... 1138 feet per second.

Olefines ................... $1155 \quad "$

Other hydrocarbons ....... $1182 \quad ", \quad "$

Aromatic hydrocarbons... 1243 " "

Simple ethers............... 1131,

Methylic salts $\ldots . . . . . . . .1185 \quad ", \quad "$

Ethylic salts .............. $1140 \quad, "$,

Other ethereal salts ...... 1125 " "

Anhydrides .............. $1167, "$,

The alcohols and acids, however, give a much higher velocity (1300-1800 feet per second) at their boiling-points than the above. But it is probable that these compounds are not so excoptional as might at first sight appear ; for the acids of the series $\mathrm{C}_{n} \mathrm{H}_{2 n} \mathrm{O}_{2}$ exhibit a remarkable variation in the volume-vapour which they furnish at different temperatures (Bineau). Thus, formic acid at its boiling-point $\left(101^{\circ}\right)$ has a vapour-density of 46 in place of 23 , and gains its proper bulk only at $213^{\circ}$. A similar thing also applies to acetic acid. If, therefore, these facts be taken into consideration, formic acid will show at its boiling-point a velocity of 1160 feet, and acetic acid a velocity of 1134 feet per second. Herwig has shown that ethyl-alcohol also possesses an exceptional vapourdensity at or near its boiling-point.

Pictet has recently pointed out (Compt. Rend. lxxxviii. pp. 855,1315$)$, as already stated, that there exists a simple relation between the atomic weight, coefficient of expansion, and melting-point of a solid body*. He also finds that a similar relation (Compt. Rend. lxxxviii. p. 1315) exists between the atomic weight, coefficient of expansion, and boiling-point of a liquid; thus :-

(1) The length of oscillation of liquid molecules at the

(2) $l \mathrm{~T}=\mathrm{K} n$;

$$
\text { b.-p. }=l=\frac{\alpha}{\sqrt[3]{\frac{d}{p}}},
$$

where $\alpha=$ mean coefficient of expansion between the meltingand boiling-points, $d=$ density, $k=$ constant, $T=$ boiling-point reckoned from $-273^{\circ} \mathrm{C} ., p=$ the physical molecular weight, $i$. e. those weights of different liquids which absorb equal quantities of heat on their temperature being raised from $0^{\circ}$ to $1^{\circ} \mathrm{O}$.; and this, being inversely as the specific heat, is a

* See also a paper by Wiebe on this subject in the Chemical News for September 26, 1879, p. 154 
simple multiple of the chemical or true molecular weight; $n$ is a number proportional to the number of liquid molecules in a given unit of length.

Melting-points of Carbon Compounds in general.-But little attention has been directed to the influence of atomic weight on and the relations between the melting-points of carbon compounds. It is, however, a subject which would no doubt repay careful investigation, and is especially important from the fact that this physical property is the one which renders the most service in the recognition of the solid compounds of carbon. The following relations will be of interest.

As pointed out above in speaking of boiling-points, those aromatic hydrocarbons containing an even number of methyl groups are solid, whilst those containing an odd number are liquid. A similar thing applies to the chlorine, and doubtless to other derivatives of benzene; for those containing an odd number of $\mathrm{Cl}$ atoms melt much lower than those with an even number, thus :-

\begin{tabular}{|c|c|c|c|c|c|c|c|}
\hline & $\mathrm{O}_{6} \mathrm{H}_{6}$. & $\mathrm{C}_{6} \mathrm{H}_{5} \cdot \mathrm{Cl}$. & $\mathrm{O}_{6} \mathrm{H}_{1} \cdot \mathrm{Cl}_{2}$ & $\mathrm{C}_{6} \mathrm{H}_{3} \cdot \mathrm{Cl}_{3}$. & $\mathrm{C}_{6} \mathrm{H}_{2}, \mathrm{Cl}_{4}$ & $\mathrm{C}_{6} \mathrm{H} . \mathrm{Cl}_{5}$. & $\mathrm{C}_{6} \mathrm{Cl}_{6}$. \\
\hline $\left.\begin{array}{c}\text { Melting- } \\
\text { point. }\end{array}\right\}=$ & $3^{\circ}$ & $-40^{\circ}$ & $53^{\circ}$ & $17^{\circ}$ & $139^{\circ}$ & $74^{\circ}$ & $26^{\circ}$ \\
\hline
\end{tabular}

The difference between those compounds containing an odd number of $\mathrm{Cl}$ atoms is constant, viz. $57^{\circ}$, and also the difference between those containing an even number of $\mathrm{Cl}$ atoms, viz. $86^{\circ}$. These facts, as previously intimated, probably depend on the symmetrical or asymmetrical arrangement of the Cl atoms.

As a general rule, the melting-points of a series of homologous compounds rise as we ascend in the series; but there is one remarkable case known in which the reverse is the case, thus:-

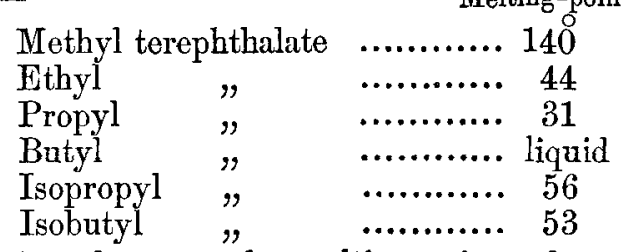

The relations between the melting-points of organic compounds and their chemical composition offer so wide a field of investigation, and one which has been so little touched, that it is my intention at an early date to trace these relations as completely as possible, especially as regards the influence of the position of the atoms, and more particularly with respect to the influence of symmetry. I have already worked a good 
deal at this subject, and have come to the following conclusions:-

(1) The melting-points of those compounds the atoms of which are symmetrically arranged, are higher than in the case of compounds in which the atomic arrangement is asymmetrical. (2) The stability (and therefore the heat of formation) of symmetrical compounds is greater than that of asymmetrical compounds isomeric with them. If this be true, then it would follow that the heats of combustion of the former compounds are less than those of the latter.

The application of the first of these conclusions may be made, first, to isomeric compounds, and, secondly, to compounds belonging to the same homologous series; whilst the second refers of course only to isomeric compounds. I reserve, however, the details of this investigation for a future communication. Since working this subject out at some length, I have noticed that $\mathrm{Mr}_{\mathrm{r}}$. Henry Watts, F.R.S., in the last Supplement (vol. viii. p. 221) of his 'Dictionary of Chemistry' has shown in a very clear and decisive manner that "The more symmetrical the constitution of a benzene derivative, the greater is the resistance which it offers to the passage from the solid to the liquid state," or, in other words, the higher the melting-point.

Freezing-points of Saline Solutions.-De Coppet (Ann. Chim. Phys. [4] xxiii. p. 366, xxv. p. 502, xxvi. p. 98) has shown, as the result of a long series of experiments, that for bodies belonging to the same molecular group the coefficient of depression of the freezing-point is inversely as the molecular weight; i. e. the molecular depressions of the freezing-point are equal. A similar relation also exists between the molecular weights of salts and the lowering of their temperatures of maximum density, and affords for the solutions of a large number of salts the means of calculating the temperature at which they freeze, and also that at which they possess a maximum density. For a large number of bodies also the molecular depression of the temperature of maximum density is nearly four times as great as the molecular depression of the freezing-point. The first of these statements is illustrated as follows:-

\begin{tabular}{|c|c|c|c|}
\hline & $\begin{array}{c}\text { Molecular } \\
\text { weight. } \\
\text { A. }\end{array}$ & $\begin{array}{l}\text { Coefficient of } \\
\text { depression of } \\
\text { freezing-point, } h \text {. }\end{array}$ & $\begin{array}{c}\text { Molecular } \\
\text { depression } \\
\mathrm{A} \times \hbar .\end{array}$ \\
\hline KCl ..... & $74 \cdot 6$ & .451 & $33 \cdot 67$ \\
\hline $\mathrm{KBr} . . .$. & $119 \cdot 1$ & $\cdot 292$ & $34 \cdot 8$ \\
\hline KI....... & $166^{\circ} 0$ & $\cdot 212$ & $35 \cdot 2$ \\
\hline $\mathrm{KNO}_{3} \ldots$ & $101 \cdot 0$ & $\cdot 267$ & $27 \cdot 0\}$ \\
\hline $\mathrm{NaNO}_{3} .$. & $85 \cdot 0$ & $\cdot 310$ & $26 \cdot 4\}$ \\
\hline
\end{tabular}




\section{Influence of Atomic Weight.}

Raoult (Compt. Rend. lxxxvii. p. 167) has further shown that the property which anhydrous salts possess of diminishing the vapour-tension of their solutions and of lowering their solidifying-point appears to be inversely as their molecular weights.

Division of a Body between two Solvents. - From his experiments on the division of a body between two solvents, Berthelot (Ann. Chim. Phys. [4] xxvi. p. 408) concludes, with regard to the relations between the coefficient of division and the chemical composition of the substance dissolved, that ether removes from water with greater facility:- (1) the more highly carburetted of two homologous acids; (2) a monobasic acid more easily than the corresponding dibasic acid, as acetic rather than oxalic ; (3) a monobasic acid rather than a dibasic acid of nearly the same composition, as acetic rather than succinic. (4) Of two acids containing the same proportion of carbon and hydrogen, that with the smallest number of $\mathrm{O}$ atoms is the more easily removed, as succinic, $\mathrm{C}_{4} \mathrm{H}_{6} \mathrm{O}_{4}$, rather than malic, $\mathrm{C}_{4} \mathrm{H}_{6} \mathrm{O}_{5}$, or tartaric, $\mathrm{C}_{4} \mathrm{H}_{6} \mathrm{O}_{6}$.

Molecular or Specific Volumes $\left(=\frac{\text { molecular weight }}{\text { specific gravity }}\right)$.Schroeder (Pogg. Ann. clx. p. 199) has proposed the hypothesis that "All bodies combine in whole volumes." In the case of gaseous bodies this can be proved, as is well known, without exception by reducing to a common temperature and pressure (Gay-Lussac). For liquids, Kopp (Ann. Chem. Pharm. xevi. pp. 153, 303) has shown that the volumes of C, $\mathrm{H}, \mathrm{O}$, and other elements in organic liquids are equal in all compounds if their specific gravity be determined at the boiling-point. The following are his more important results:(1) Differences of molecular volume are proportional to the differences between the corresponding chemical formula. Thus the difference of $\mathrm{CH}_{2}$ in homologous series corresponds to a difference of 22 in the molecular volume, thus:-

\begin{tabular}{|c|c|c|}
\hline $\begin{array}{cc} & \text { Molecular } \\
\text { weight. }\end{array}$ & $\begin{array}{l}\text { Specific } \\
\text { volume. }\end{array}$ & Difference. \\
\hline $\begin{array}{l}\text { Formic acid.......... } 46 \\
\text { Acetic }\end{array}$ & 42 & $\overline{\Omega 0}$ \\
\hline $\begin{array}{lll}\text { Acetic } & \text {......... } & 60 \\
\text { Propionic acid...... } & 74\end{array}$ & 64 & 22 \\
\hline 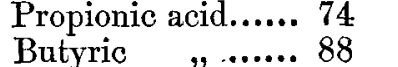 & 86 & 22 \\
\hline Butyric $\quad, \ldots \ldots . .88$ & 108 & 22 \\
\hline
\end{tabular}

(2) Isomeric liquids belonging to the same chemical type have equal molecular volumes. Thus $\left.\mathrm{C}_{2} \mathrm{H}_{3} \mathrm{O}\right\} \mathrm{H}$ and $\left.\mathrm{CHO}_{\mathrm{CH}^{3}}\right\} \mathrm{O}$ have the same molecular volume, viz. $63 \cdot 4$. (3) Compounds containing as many times two atoms of $\mathrm{H}$ less, as others contain 
one atom of $\mathrm{C}$ more, have the same molecular volume; or, the volume of one atom of $\mathrm{C}$ is equal to that of two atoms of $\mathrm{H}$ thus :-

$\left\{\begin{array}{ccc}\begin{array}{c}\text { Molecular } \\ \text { weight. }\end{array} & \begin{array}{c}\text { Molecular } \\ \text { volume. }\end{array} \\ \mathrm{C}_{8} \mathrm{H}_{18} & 114 & 187 \\ \mathrm{C}_{10} \mathrm{H}_{14} & 134 & 187 \\ \mathrm{C}_{4} \mathrm{H}_{10} \mathrm{O} & 74 & 106 \cdot 8 \\ \mathrm{C}_{6} \mathrm{H}_{6} \mathrm{O} & 94 & 106 \cdot 8\end{array}\right\}$

Now it has already been shown that the volume of $\mathrm{CH}_{2}=22$; therefore the specific volume of $\mathrm{C}=11$, and that of $\mathrm{H}=5 \cdot 5$.

In liquids belonging to different types, the volume of the oxygen varies according to the manner in which it is combined in the compound. When the $\mathrm{O}$ is joined on to $\mathrm{C}$ by one combining power only, its specific volume $=7 \cdot 8$; but when attached to $\mathrm{C}$ by both its combining powers, its specific volume $=12 \cdot 2$. A similar thing occurs in the case of $\mathrm{S}$ : its specific volume in the former case being 23 , and in the latter $28 \cdot 6$. The specific volume of $\mathrm{Cl}=22 \cdot 8$, of $\mathrm{Br}=27 \cdot 8$, of $\mathrm{I}=37 \cdot 5 . \quad \mathrm{N}$ in ammoniacal compounds $=2 \cdot 3$, in cyanides $=17 \cdot 0$, and in nitro-compounds $=17 \cdot 4$. By the use of these constants we may calculate the molecular volume of a compound when its molecular formula is known, thus :-

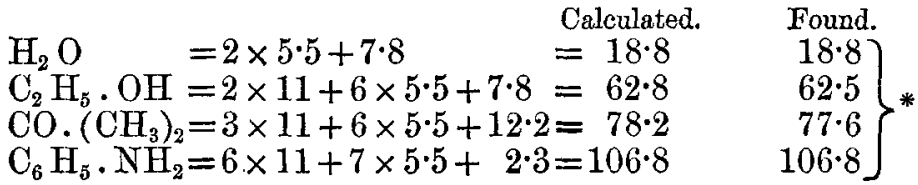

It appears then that the molecular volume depends not only on the chemical composition, but also on the constitution or arrangement of the atoms in the molecules.

As regards the molecular volume of solids, Kopp (Pogg. Ann. xlvii. p. 133 ; lii. pp. 243, 262), and more especially Schroeder (ibid. l. p. 552, lii. pp. 269, 282, cvi. p. 226, cvii: p. 113), have endeavoured to show that the hypothesis that all bodies combine in whole volumes holds good not only for gases and liquids, but also in the case of solids; and Schroeder has pointed out that "equivalent quantities of different elements in uniting with the same quantity of a given element (or compound radical) receive equal increments of volume." The explanation of this appears to be that certain elements enter into combination with the same volume which they occupy in the free state. More recently Schroeder (Deut. chem. Ges.

* Schorlemmer's 'Chemistry of the Carbon Compounds.' 
Ber. vii. p. 676 , ix. p. 1188 , x. pp. 848,1871 , xi. pp. 1109 , 1142, 2017, 2128, xii. p. 119; Pogg. Ann. clx. p. 199) has shown that when an element like silver and a series of its compounds have volumes which stand exactly to one another in simple relations, then they have equal volume-masses or equal steres. Every volume may in fact be represented as a simple multiple of a common volume-mass or stere. So that, "In every solid compound the volume-measure or stere of one of its elements determines all the other components, and causes equal volume-measures to take up equal steres." In other words, one of the elements of a compound impresses its own volumemass or stere on the whole compound, and becomes the controlling element in a whole series of otherwise very different compounds. Thus :-

$$
\begin{array}{ll}
\begin{array}{c}
\text { Calculated } \\
\text { volume. }
\end{array} & \begin{array}{c}
\text { Observed } \\
\text { volume. }
\end{array} \\
\mathrm{Ag}_{1}^{2}=2 \times 5 \cdot 14=10 \cdot 28 & =10 \cdot 28 \\
\mathrm{Ag}_{1}^{2} \mathrm{Cl}_{3}^{3}=5 \times 5 \cdot 14=25 \cdot 70 & =25 \cdot 70 \\
\mathrm{Ag}_{1}^{2} \mathrm{Br}_{1}^{4}=6 \times 5 \cdot 14=30 \cdot 84 & =30 \cdot 84 \\
\mathrm{Ag}_{1}^{2} \mathrm{I}_{1}^{6}=8 \times 5 \cdot 14=41.12 & =41.12
\end{array}
$$

In the above examples the number of atoms in a compound is indicated in the usual way by a number placed to the right and under side of a symbol, and the number of its steres by a number at the right of the upper side. Here in these compounds it is seen that silver is the predominating element; for it impresses its stere $(=5 \cdot 14)$ on all the other compounds. By the use of this law Schroeder has endeavoured, with some success, to determine the molecular weight of a solid body; for if substances combine only in whole volumes, then the molecule of a body must contain the number of atoms which are necessary for the components of the compound to fill the space of the whole number of volume-units. He also shows that in many compounds which are capable of existing in more than one form, the difference in form depends on which is the dominating element in the compound. Thus black cinnabar is distinguished from the red by the fact that in the former the mercury stere dominates, whilst in the latter it is the sulphur stere.

[To be continued.] 